\title{
Endocrine comorbidities of pediatric obesity
}

Jieun Lee, MD ${ }^{1}$, Jae Hyun Kim, MD, PhD ${ }^{2,3}$

${ }^{1}$ Department of Pediatrics, Inje University Ilsan Paik Hospital, Goyang, Korea; ${ }^{2}$ Department of Pediatrics, Seoul National University Bundang Hospital, Seongnam, Korea; ${ }^{3}$ Department of Pediatrics, Seoul National University College of Medicine, Seoul, Korea

Pediatric obesity has become a serious public health issue. The prevalence of obesity in children and adolescents has in creased worldwide and in Korea over several decades. Obese children are more likely to be obese adults with an increased cardiovascular risk. Therefore, maintaining a healthy weight and preventing obesity during childhood are of critical importance. Moreover, obese children and adolescents often have endocrine comorbidities such as prediabetes, type 2 diabetes, dyslipidemia, metabolic syndrome, polycystic ovary syndrome, and central precocious puberty. Hence, the early implementation of obesity management using a multidisciplinary team approach and screening for these comorbidities in obese children and adolescents are required with the appropriate management of each comorbidity and/or specialist referral.

Key words: Obesity, Comorbidities, Endocrine, Child, Adolescent

\section{Key message}

- Pediatric obesity can involve endocrine comorbidities such as prediabetes, type 2 diabetes, dyslipidemia, metabolic syndrome, polycystic ovary syndrome, and central precocious puberty.

- Prediabetes and type 2 diabetes in youth aged 10-19 years had a prevalence of $25.9 \%$ and $0.6 \%$ in $2013-2014$, respectively.

- Dyslipidemia in Korean adolescents aged 10-18 years had a prevalence of $7.64 \%$ (total cholesterol $\geq 200 \mathrm{mg} / \mathrm{dL}$ ), $6.09 \%$ (low-density lipoprotein cholesterol $\geq 130 \mathrm{mg} / \mathrm{dL}$ ), $8.69 \%$ (triglyceride $\geq 150 \mathrm{mg} / \mathrm{dL}$ ), and $12.52 \%$ (high-density lipoprotein cholesterol $\leq 40 \mathrm{mg} / \mathrm{dL}$ ) in 2007-2018.

Metabolic syndrome in Korean youth has a prevalence of $1.9 \%-14.7 \%$ in males and $1.7 \%-12.6 \%$ in females with wide variation in definitions.

Appropriate comorbidity screening and management and/ or specialist referral are necessary for obese children and adolescents.

\section{Introduction}

Obesity is a state of excessive fat accumulation. ${ }^{1)}$ Body mass index (BMI), calculated as weight in kilograms divided by height in meters squared, is commonly used to diagnose obesity. BMI is closely correlated with body fat, is easily calculated, and has reference values for comparison. In children aged 2-20 years, obesity is defined as a BMI $\geq 95$ th percentile and overweight as a BMI $\geq 85$ th percentile but $<95$ th percentile of the corresponding sex and age. ${ }^{2)}$ In children aged $<2$ years, obesity is defined as a sex-specific weight for a length $\geq 97.7$ th percentile. ${ }^{2)}$

The prevalence of pediatric obesity has increased worldwide. Between 1975 and 2016, its worldwide prevalence in children and adolescents aged 2-18 years increased from $0.7 \%$ to $5.6 \%$ in girls and from $0.9 \%$ to $7.8 \%$ in boys. ${ }^{3)}$ In Korea, the prevalence of obesity in the pediatric population aged 2-18 years increased from 5.8\% in 1997 to $9.7 \%$ in 2005.4) Among school-aged children aged 6-18 years, the prevalence of obesity progressively increased from $8.7 \%$ in 2007 to $15.0 \%$ in 2017.5$)$ Extreme obesity has increased significantly among children and adolescents aged $10-19$ years, especially among boys. ${ }^{6}$

Pediatric obesity has become a serious public health issue. Obese children are more likely to be obese adults. In a metaanalysis, the pooled relative risk for adult obesity among obese children is more than 5 times higher than that among their nonobese counterparts. ${ }^{7}$ Moreover, pediatric obesity increases one's cardiovascular risk in adulthood. ${ }^{8)}$ Recent epidemiological studies demonstrated an association between childhood obesity and an increased risk of several cancers in adulthood, such as leukemia, Hodgkin's disease, colorectal cancer, and breast cancer. $\left.{ }^{9} 10\right)$ The lifetime costs for those with a history of childhood obesity are 3-5 times higher than those of their nonobese counterparts. ${ }^{11,12)}$ Pediatric obesity is accompanied by many comorbidities, including those in the endocrine, pulmonary, cardiovascular, gastrointestinal, renal, and/or other systems. ${ }^{2)}$

This review article discusses the endocrine comorbidities of pediatric obesity, such as prediabetes, type 2 diabetes (T2D), dyslipidemia, metabolic syndrome (MS), polycystic ovary syn-

\footnotetext{
Corresponding author: Jae Hyun Kim, MD, PhD. Department of Pediatrics, Seoul National University Bundang Hospital, Seoul National University College of Medicine, 82, Gumi-ro 173 Beon-gil, Bundang-gu, Seongnam 13620, Korea 


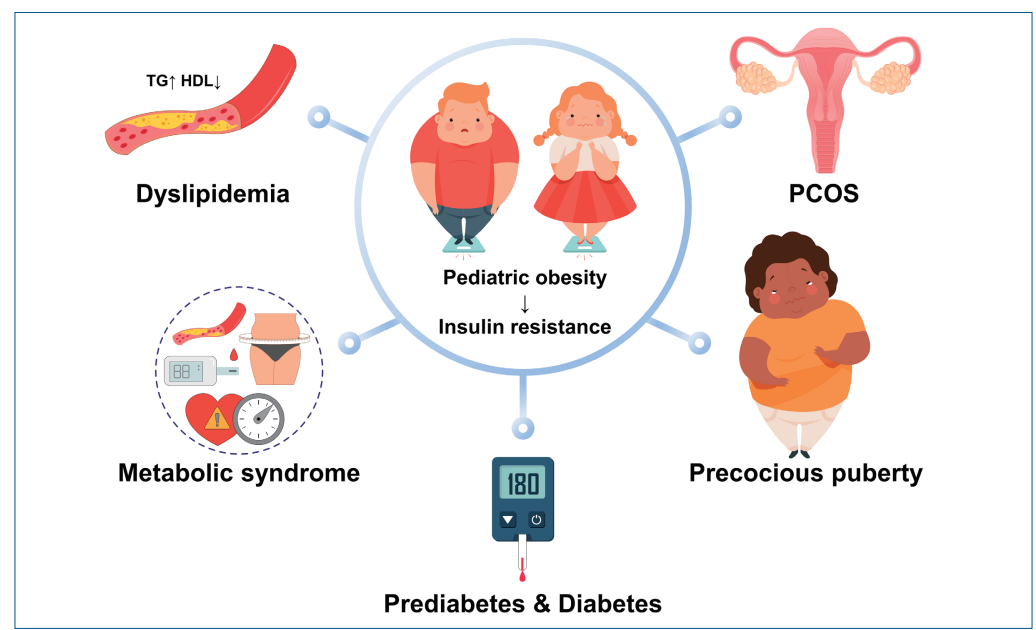

Graphic abstract

drome (PCOS), and central precocious puberty (CPP).

\section{Prediabetes and T2D}

Diabetes mellitus is a disease characterized by chronic hyperglycemia caused by abnormal insulin secretion or resistance that results in metabolic disturbances. ${ }^{13)}$ Prediabetes is a state with high blood glucose levels between normoglycemia and diabetes that indicates an increased risk of developing diabetes, including impaired fasting glucose, impaired glucose tolerance, elevated glycated hemoglobin (HbA1c), or a combination thereof. ${ }^{14)}$ Both prediabetes and diabetes are associated with cardiovascular diseases (CVDs) in adulthood.

Pediatric obesity is associated with an increased risk of prediabetes and diabetes, especially T2D. ${ }^{15)}$ Obesity increases insulin resistance in the skeletal muscles, liver, and adipose tissues, leading to prediabetes and T2D. ${ }^{13)}$ Excessive ectopic fat accumulation in the skeletal muscles and liver exacerbates peripheral insulin resistance. ${ }^{16)}$ Insulin resistance causes decreased glucose disposal in the skeletal muscles, increased glucose production in the liver, and the increased production of free fatty acids (FFAs) and inflammatory cytokines in the adipose tissues. ${ }^{17)}$ Beta cell function and mass are also gradually decreased due to glucotoxicity, lipotoxicity, mitochondrial dysfunction, and endoplasmic reticular stress. ${ }^{18)} \mathrm{T} 2 \mathrm{D}$ in children and adolescents differs from adult-onset T2D, including the early deterioration of beta cell function and rapid development of diabetic complications. ${ }^{19,20)}$

Diabetes and prediabetes are diagnosed according to American Diabetes Association (ADA) guidelines. ${ }^{14)}$ Prediabetes is defined as a fasting plasma glucose $\geq 100 \mathrm{mg} / \mathrm{dL}$ but $<126 \mathrm{mg} /$ $\mathrm{dL}$, a 2-hr glucose level after an oral glucose tolerance test $\geq 140$ $\mathrm{mg} / \mathrm{dL}$ and $<200 \mathrm{mg} / \mathrm{dL}$, or a HbA1c level $\geq 5.7 \%$ but $<6.5 \%$. Diabetes is defined as a fasting plasma glucose $\geq 126 \mathrm{mg} / \mathrm{dL}$, a 2-hr glucose level after an oral glucose tolerance test $\geq 200 \mathrm{mg} /$ $\mathrm{dL}$, an $\mathrm{HbA} 1 \mathrm{c} \geq 6.5 \%$, or a random glucose level $\geq 200 \mathrm{mg} / \mathrm{dL}$ with classical symptoms including fatigue, polyuria, and weight loss. The usefulness of $\mathrm{HbA1c}$ for the diagnosis of prediabetes and T2D in pediatric patients has yet to be determined. ${ }^{14,21)}$

$\mathrm{ADA}$ and the International Society for Pediatric and Adolescent Diabetes recommend risk-based screening strategies for prediabetes and T2D in asymptomatic youth. ${ }^{14,22)}$ Overweight or obese youth with 1 or more of the following risk factors, who are in puberty or aged $\geq 10$ years, are recommended to undergo screening: maternal diabetes or gestational diabetes; family history of diabetes; signs of or conditions related to insulin resistance, including acanthosis nigricans, hypertension, dyslipidemia, PCOS, or born small for gestational age; or race/ ethnicity. ${ }^{14,22)}$ Screening tests include fasting plasma glucose, 2-hour plasma glucose after an oral glucose tolerance test, and HbA1c. ${ }^{23)}$ Follow-up tests are recommended at least at 3-year intervals when the test result is normal. However, more frequent tests are required if the individual's BMI increases or other risk factors worsen. ${ }^{14,22)}$

Recent epidemiologic data revealed an increasing prevalence of pediatric prediabetes and T2D along with an increase in obesity (Table 1). ${ }^{13)}$ In the United States (US), among pediatric diabetes cases, the prevalence of T2D in children and adolescents increased from approximately $3 \%$ in the early 1990 s to $20 \%$ in $2003^{24,25)}$; the prevalence of prediabetes in youth aged 12-18 years was $18.0 \%$ in $\left.2005-2016 .{ }^{26}\right)$ In Korea, the estimated prevalence of prediabetes and T2D in youth aged 10-19 years according to nationally representative data showed an increasing tendency from $0.6 \%$ in 2005 to $25.9 \%$ in 2013-2014 for prediabetes and from $0.1 \%$ in 2007 to $0.6 \%$ in $2013-2014$ for T2D. ${ }^{27)}$ In China, the prevalence of impaired fasting glycemia and T2D showed more than a 2 -fold increase between 2002 and 2012. ${ }^{28)}$

Consensus is lacking on the treatment of children and adolescents with prediabetes. However, lifestyle modifications are generally recommended, including a balanced and healthy diet, increased physical activity, and decreased sedentary behavior. ${ }^{29)}$ In pediatric patients with T2D, lifestyle management and 
Table 1. Definition and prevalence of prediabetes and type 2 diabetes mellitus in children and adolescents

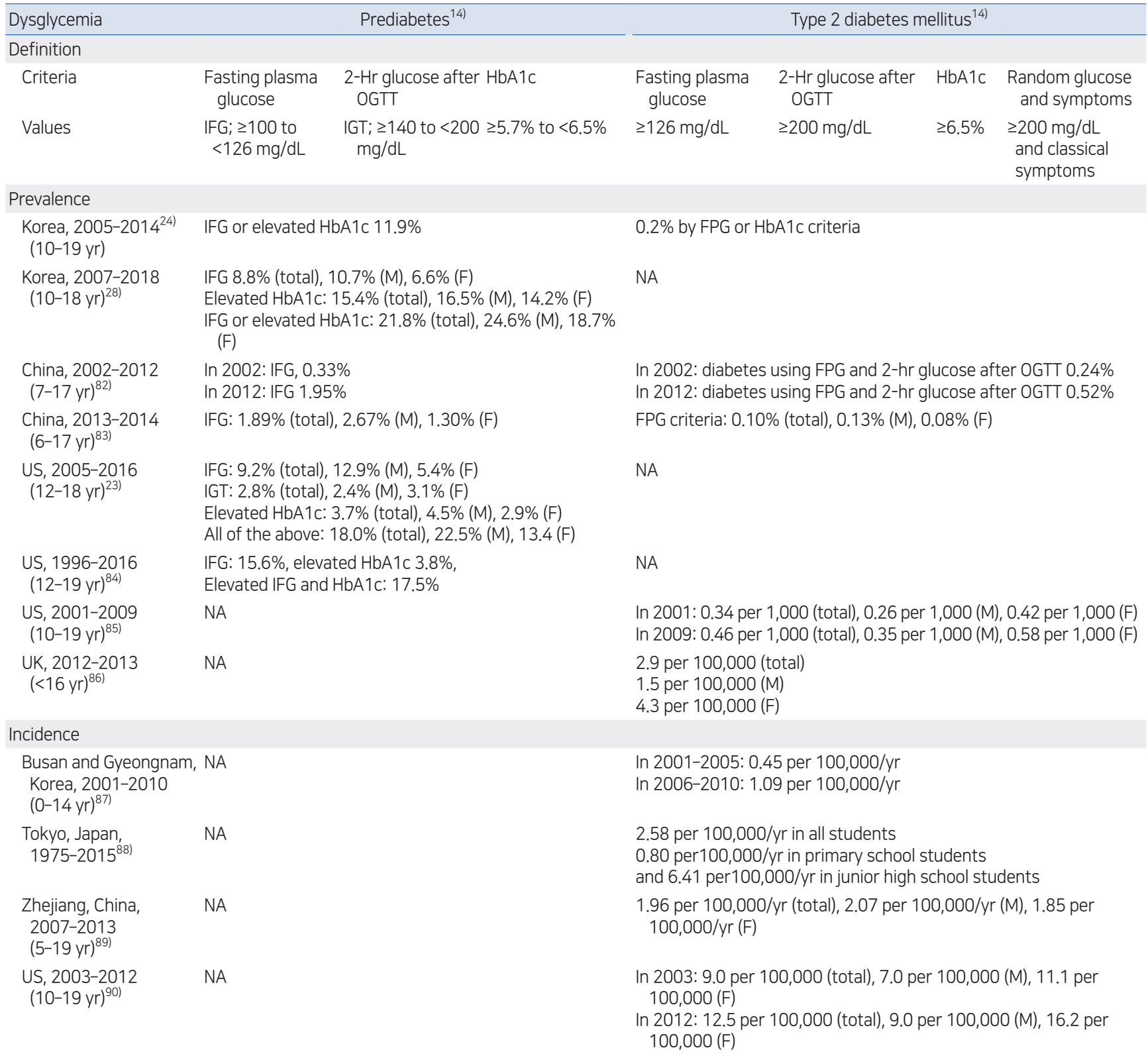

HbA1C, glycated hemoglobin; OGTT, oral glucose tolerance test; M, male; F, female; IFG, impaired fasting glucose; IGT, impaired glucose tolerance; NA, not available; FPG, fasting plasma glucose; NA, not available.

diabetes education should be initiated at the time of diagnosis. 22,30) Metformin and insulin, alone or in combination, are used for pharmacologic treatment of T2D. ${ }^{22)}$ The choice of initial pharmacologic treatment depends on the severity of hyperglycemia and metabolic disturbances such as acidosis or ketosis. $^{22)}$

The glycemic target for youth with T2D is an HbA1c level $<7 \%$, although the level should be individualized according to a patient's circumstances. ${ }^{31)}$ If glycemic targets are not met, increments in the dose of metformin and the addition or titration of insulin dose should be implemented. If HbA1c targets are not met with metformin and insulin, liraglutide might be considered. ${ }^{32)}$ However, as of early 2020, this drug was not yet approved for adolescents in Korea. Metabolic bariatric surgery is selectively and limitedly considered in cases of uncontrolled T2D with severe obesity and serious comorbidities. ${ }^{33)}$

To prevent diabetic complications, the measurement of blood pressure at each visit and annual urinary albumin-to-creatinine ratio, fasting lipid panel, and retinal examinations should be performed after the diagnosis of T2D is made. ${ }^{34)}$

\section{Dyslipidemia}

Dyslipidemia, abnormal blood lipid levels caused by disordered lipoprotein metabolism, ${ }^{35)}$ is a risk factor for CVD and among the main causes of mortality and morbidity in adults. ${ }^{35)}$ Since dyslipidemia and atherosclerotic vascular changes also 
Table 2. Definition and prevalence of dyslipidemia in children and adolescents

\begin{tabular}{|c|c|c|c|c|c|c|}
\hline Dyslipidemia $^{37,38)}$ & Total cholesterol & LDL cholesterol & Non-HDL cholesterol & $\begin{array}{c}\text { Triglyceride } \\
\text { (0-9 yr) }\end{array}$ & $\begin{array}{c}\text { Triglyceride } \\
\text { (10-19 yr) }\end{array}$ & HDL cholesterol \\
\hline \multicolumn{7}{|l|}{ Cutoff values } \\
\hline Acceptable (mg/dL) & $<170$ & $<110$ & $<120$ & $<75$ & $<90$ & $>45$ \\
\hline Borderline (mg/dL) & 170-199 & $110-129$ & $120-144$ & $75-99$ & 90-129 & $40-45$ \\
\hline Abnormal (mg/dL) & $\geq 200$ & $\geq 130$ & $\geq 145$ & $\geq 100$ & $\geq 130$ & $<40$ \\
\hline Prevalence of abnormal lipid values & Total cholesterol & LDL cholesterol & Non-HDL cholesterol & \multicolumn{2}{|c|}{ Triglyceride } & HDL cholesterol \\
\hline \multirow[t]{3}{*}{ Korea, 2007-2009 34$)(10-18 \text { yr })^{a)}$} & $6.5 \%$ (total) & $4.7 \%$ (total) & NA & \multicolumn{2}{|c|}{$10.1 \%$ (total) } & $7.1 \%$ (total) \\
\hline & $5.8 \%(M)$ & $4.1 \%(M)$ & NA & \multicolumn{2}{|c|}{$9.8 \%(M)$} & $8.5 \%(M)$ \\
\hline & $7.4 \%(F)$ & $5.5 \%(F)$ & NA & \multicolumn{2}{|c|}{$10.3 \%(F)$} & $5.5 \%(F)$ \\
\hline \multirow[t]{3}{*}{ Korea, 2007-2018 (10-18 yr ${ }^{28), b)}$} & $7.64 \%$ (total) & $6.09 \%$ (total) & 8.39\% (total) & \multicolumn{2}{|c|}{$8.69 \%$ (total) } & $12.52 \%$ (total) \\
\hline & $5.98 \%(M)$ & $4.97 \%(M)$ & $7.22 \%(M)$ & \multicolumn{2}{|c|}{$8.85 \%(M)$} & $15.36 \%(M)$ \\
\hline & $9.52 \%(F)$ & $7.37 \%(F)$ & $9.73 \%(F)$ & \multicolumn{2}{|c|}{$8.50 \%(F)$} & $9.30 \%(F)$ \\
\hline \multirow[t]{3}{*}{ US, 1999-2012 ${ }^{35)}(8-17 y r)$} & $7.8 \%$ (total) & NA & $8.4 \%$ (total) & \multicolumn{2}{|c|}{ NA } & $12.8 \%$ (total) \\
\hline & $6.6 \%(M)$ & NA & $7.5 \%(M)$ & \multicolumn{2}{|l|}{ NA } & $12.6 \%(M)$ \\
\hline & $9.0 \%(F)$ & NA & $9.2 \%(F)$ & \multicolumn{2}{|l|}{ NA } & $12.9 \%(F)$ \\
\hline \multirow[t]{3}{*}{ Beijing, China, 2014 ${ }^{91)}(6-18$ yr) } & $10.7 \%$ (total) & $5.8 \%$ (total) & $7.6 \%$ (total) & \multicolumn{2}{|c|}{$16.1 \%$ (total) } & $6.4 \%$ (total) \\
\hline & $10.7 \%(M)$ & $5.3 \%(M)$ & $7.0 \%(M)$ & \multicolumn{2}{|c|}{$15.4 \%(M)$} & $8.5 \%(M)$ \\
\hline & $10.7 \%(F)$ & $6.4 \%(F)$ & $8.4 \%(F)$ & \multicolumn{2}{|c|}{$17.0 \%(F)$} & $3.8 \%(F)$ \\
\hline
\end{tabular}

LDL, low-density lipoprotein; HDL, high-density lipoprotein; NA, not available; M, male; F, female.

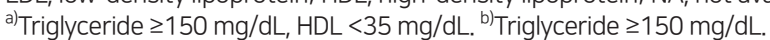

begin in childhood and adolescence, ${ }^{36}$ the early detection and proper management of dyslipidemia could prevent atherosclerosis and CVD in adulthood.

Dyslipidemia includes elevated total cholesterol, low-density lipoprotein cholesterol (LDL-C), triglyceride, non-high-density lipoprotein cholesterol (non-HDL-C) levels, and a decreased HDL-C level. Lipid levels in children and adolescents are classified as acceptable, borderline, or abnormal (Table 2). The cutoff values were derived from population-based studies and are used in several guidelines. ${ }^{37,38)}$

Obesity is a risk factor for dyslipidemia. ${ }^{39}$ Lipid abnormalities commonly observed in obese populations are elevated trigly. cerides, very LDL (VLDL), apolipoprotein B, and non-HDL-C and decreased HDL-C. ${ }^{39)}$ Insulin resistance, visceral adiposity, and a proinflammatory state in obesity are associated with increased basal lipolysis in the adipose tissues, which leads to elevated circulating FFA levels. ${ }^{39)}$ An increased influx of FFAs to the liver contributes to the hepatic overproduction of VLDL particles. Serum triglyceride levels increase due to increases in VLDL particles and the decreased clearance of triglyceridecontaining lipoproteins. ${ }^{39)}$ Increased triglyceride levels are associated with decreased HDL-C levels via cholesteryl ester transfer protein-mediated reciprocal exchange. ${ }^{39)}$

The prevalence of dyslipidemia in Korean adolescents aged $10-18$ years was $6.5 \%$ for total cholesterol $\geq 200 \mathrm{mg} / \mathrm{dL}, 4.7 \%$ for LDL-C $\geq 130 \mathrm{mg} / \mathrm{dL}, 10.1 \%$ for triglyceride $\geq 150 \mathrm{mg} /$ $\mathrm{dL}$, and 7.1\% for HDL-C $<35 \mathrm{mg} / \mathrm{dL}$ in $2007-2009 .{ }^{40)}$ The prevalence of dyslipidemia in US children and adolescents aged 8-17 years decreased between 1999-2000 and 2011-2012: $10.6 \%$ to $7.8 \%$ for total cholesterol $\geq 200 \mathrm{mg} / \mathrm{dL}$ and $13.6 \%$ to $8.4 \%$ for non-HDL-C $\geq 145 \mathrm{mg} / \mathrm{dL} .{ }^{41)}$ However, the prevalence of dyslipidemia increased with the degree of obesity in US children and young adults. ${ }^{8)}$

Several guidelines for dyslipidemia in children and adolescents recommend "universal screening" at the ages of 9-11 and 17-21 years using nonfasting non-HDL-C testing. ${ }^{37,38,42)}$ However, since obesity is a risk factor for dyslipidemia, lipid screening in obese children and adolescents is required at age $\geq 2$ years. If nonfasting non-HDL-C is $\geq 145 \mathrm{mg} / \mathrm{dL}$, a fasting lipid panel should be performed twice within 3 months. ${ }^{37,38)}$ The average values are used for management decisions.

The management of dyslipidemia in children and adolescents begins with lifestyle changes including diet and exercise. ${ }^{37)}$ The Cardiovascular Health Integrated Lifestyle Diet (CHILD-1) is recommended for children aged $\geq 2$ years. If the fasting lipid profile remains abnormal for 6 months, the CHILD-2-LDL or CHILD-2-TG diet should be applied according to the lipid abnormalities. ${ }^{37}$ Along with dietary management, moderate to vigorous physical activity for at least 1 hour daily and decreased sedentary time are essential. ${ }^{37)}$

Pharmacologic treatment for children and adolescents with dyslipidemia is generally recommended for those aged $\geq 10$ years who show a poor response to lifestyle modifications. Treatment with statins is recommended for those with an elevated LDL-C $(\geq 190 \mathrm{mg} / \mathrm{dL}$ ); an LDL-C of $160-189 \mathrm{mg} / \mathrm{dL}$ with a family history, $\geq 1$ high-risk factor, or $\geq 2$ moderate-risk factors; or an LDL-C of $130-159 \mathrm{mg} / \mathrm{dL}$ with $\geq 2$ high-risk factors, 1 highrisk factor and $\geq 2$ moderate-risk factors, or clinical CVD. ${ }^{37)}$ For those with elevated triglyceride levels, omega-3 fish oil or fibric acid derivatives must be considered. ${ }^{37)}$ The treatment target for LDL-C is $<130 \mathrm{mg} / \mathrm{dL}$. Fasting lipid profiles and the evaluation of adverse effects must be performed regularly. ${ }^{37}$ ) 
Table 3. Definition and prevalence of metabolic syndrome

\begin{tabular}{|c|c|c|c|c|}
\hline Metabolic syndrome & Cook et al. ${ }^{46)}$ & De Ferranti et al. ${ }^{48)}$ & IDF $(10-<16 y r)^{40)}$ & $\operatorname{IDF}(\geq 16 \mathrm{yr})^{40)}$ \\
\hline \multicolumn{5}{|l|}{ Definition } \\
\hline Diagnostic criteria & $\geq 3$ of 5 criteria below & $\geq 3$ of 5 criteria below & \multicolumn{2}{|l|}{$\begin{array}{l}\text { Central obesity with } \geq 2 \\
\text { of remaining } 4 \text { criteria }\end{array}$} \\
\hline Waist circumference & $\geq 90$ th percentile & $\geq 75$ th percentile & $\geq 90$ th percentile & $\geq 90 \mathrm{~cm}(\mathrm{M}), \geq 85 \mathrm{~cm}(\mathrm{~F})$ \\
\hline Blood pressure & $\geq 90$ th percentile & $\geq 90$ th percentile & $\begin{array}{l}\mathrm{SBP} \geq 130 \mathrm{mmHg} \text { or } \\
\mathrm{DBP} \geq 85 \mathrm{mmHg}\end{array}$ & $\begin{array}{l}\mathrm{SBP} \geq 130 \mathrm{mmHg} \text { or } \mathrm{DBP} \geq 85 \\
\mathrm{mmHg} \text { or previously diagnosed } \\
\text { with hypertension }\end{array}$ \\
\hline Fasting glucose & $\geq 110 \mathrm{mg} / \mathrm{dL}$ & $\geq 110 \mathrm{mg} / \mathrm{dL}$ & $\geq 100 \mathrm{mg} / \mathrm{dL}$ & $\begin{array}{l}\geq 100 \mathrm{mg} / \mathrm{dL} \text { or known type } 2 \\
\text { diabetes }\end{array}$ \\
\hline HDL cholesterol & $\leq 40 \mathrm{mg} / \mathrm{dL}$ & $\begin{array}{l}\text { Boys }<45 \mathrm{mg} / \mathrm{dL} \\
\text { Girls }<50 \mathrm{mg} / \mathrm{dL}\end{array}$ & $<40 \mathrm{mg} / \mathrm{dL}$ & $\begin{array}{l}<40 \mathrm{mg} / \mathrm{dL}(\mathrm{M}) \text { or }<50 \mathrm{mg} / \mathrm{dL}(\mathrm{F}) \\
\quad \text { or treatment for low } \mathrm{HDL}\end{array}$ \\
\hline Triglyceride & $\geq 110 \mathrm{mg} / \mathrm{dL}$ & $\geq 100 \mathrm{mg} / \mathrm{dL}$ & $\geq 150 \mathrm{mg} / \mathrm{dL}$ & $\begin{array}{l}\geq 150 \mathrm{mg} / \mathrm{dL} \text { or treatment for } \\
\text { high triglyceride }\end{array}$ \\
\hline \multicolumn{5}{|l|}{ Prevalence } \\
\hline \multirow[t]{2}{*}{ Korea, 2008-2017 (10-19 yr ${ }^{92)}$} & $2.18 \%(2008)$ & NA & \multicolumn{2}{|l|}{$1.53 \%(2008)$} \\
\hline & $3.19 \%(2017)$ & & \multicolumn{2}{|l|}{$3.19 \%$ (2017) } \\
\hline \multirow[t]{2}{*}{ Korea, 2005-2013 (12-19 yr $)^{43)}$} & $5.6 \%(M)$ & $14.7 \%(M)$ & \multicolumn{2}{|l|}{$2.0 \%(M)$} \\
\hline & $3.7 \%(F)$ & $12.6 \%(F)$ & \multicolumn{2}{|l|}{$2.0 \%(F)$} \\
\hline \multirow[t]{3}{*}{ Korea, 2010-2012 (10-18 yr $)^{44)}$} & $5.7 \%$ (total) & NA & \multicolumn{2}{|l|}{$2.1 \%$ (total) } \\
\hline & $5.8 \%(M)$ & & \multicolumn{2}{|l|}{$1.9 \%(M)$} \\
\hline & $5.5 \%(F)$ & & \multicolumn{2}{|l|}{$2.2 \%(F)$} \\
\hline \multirow[t]{3}{*}{ Korea, 2011-2014 (10-19 yr $)^{45)}$} & NA & NA & \multicolumn{2}{|l|}{$1.8 \%$ (total) } \\
\hline & & & \multicolumn{2}{|l|}{$1.9 \%(M)$} \\
\hline & & & \multicolumn{2}{|l|}{$1.7 \%(F)$} \\
\hline \multirow[t]{3}{*}{ Korea, 2007-2018 (10-18 yr $)^{28)}$} & $3.55 \%$ (total) & 10.29\% (Total) & \multicolumn{2}{|l|}{$2.01 \%$ (total) } \\
\hline & $3.93 \%(M)$ & $10.26 \%(M)$ & \multicolumn{2}{|l|}{$1.93 \%(M)$} \\
\hline & $3.11 \%(F)$ & $10.33 \%(F)$ & \multicolumn{2}{|l|}{$2.10 \%(F)$} \\
\hline US, 1988-1994 (12-19 yr $)^{41)}$ & NA & $\begin{array}{l}\text { Mexican American } 12.9 \%, \\
\text { non-Hispanic White } 10.9 \\
\%, \text { non-Hispanic Black } \\
2.5 \%\end{array}$ & \multicolumn{2}{|l|}{ NA } \\
\hline \multirow[t]{2}{*}{ US, 1999-2004 (12-17 yr $)^{46)}$} & NA & NA & \multicolumn{2}{|c|}{ 4.5\% (Total), 6.7\% (M), 2.1\% (F) } \\
\hline & & & \multicolumn{2}{|c|}{$\begin{array}{l}\text { White } 4.5 \% \text {, African American 3.0\%, Mexican American } \\
7.1 \%\end{array}$} \\
\hline \multirow[t]{3}{*}{ US, 1999-2012 (12-19 yr) $)^{43)}$} & $\begin{array}{l}\text { Mexican American: } 8.9 \% \\
(\mathrm{M}), 5.6 \%(\mathrm{~F})\end{array}$ & $\begin{array}{l}\text { Mexican American: } 18.7 \% \\
(\mathrm{M}), 15.3 \%(\mathrm{~F})\end{array}$ & \multicolumn{2}{|c|}{ Mexican American 10.9\% (M), 5.6\% (F) } \\
\hline & $\begin{array}{l}\text { Non-Hispanic White: } 7.8 \% \\
\text { (M), } 5.0 \% \text { (F) }\end{array}$ & $\begin{array}{l}\text { Non-Hispanic White: } 13.9 \% \\
\text { (M), } 11.1 \%(F)\end{array}$ & \multicolumn{2}{|c|}{ Non-Hispanic White 6.1\% (M), 3.3\% (F) } \\
\hline & $\begin{array}{l}\text { Non-Hispanic Black: } 2.6 \% \\
(\mathrm{M}), 2.6 \%(\mathrm{~F})\end{array}$ & $\begin{array}{l}\text { Non-Hispanic Black: } 8.4 \% \\
(\mathrm{M}), 6.5 \%(\mathrm{~F})\end{array}$ & \multicolumn{2}{|c|}{ Non-Hispanic Black 2.4\% (M), 3.7\% (F) } \\
\hline China, 2007-2011 (10-17 yr $)^{93)}$ & $3.83 \%$ & NA & \multicolumn{2}{|l|}{ NA } \\
\hline $\begin{array}{l}10 \text { European cities, 2006-2007 } \\
(12.5-17 \mathrm{yr})^{94)}\end{array}$ & $3.5 \%$ & NA & \multicolumn{2}{|l|}{$2.7 \%$} \\
\hline Brazil, 2014-2015 (12-17 yr $)^{95)}$ & $1.9 \%$ & $5.0 \%$ & $2.1 \%$ & \\
\hline
\end{tabular}

\section{Metabolic syndrome}

MS is defined as a constellation of several cardiometabolic risk factors. The concept of MS was first described by Raven in 1988 as a cluster of cardiometabolic risk factors associated with insulin resistance; he named it "syndrome X." "3) In 2001, the term "metabolic syndrome" was first used by the National Cholesterol Education Program-Adult Treatment Panel III (NCEP-ATP III), with the presence of 3 of 5 components including abdominal obesity, hypertension, hyperglycemia, hypertriglyceridemia, and a low HDL-C level. ${ }^{44)}$ Since then, several definitions for the diagnosis of MS have emerged for adult and pediatric populations.

In the pediatric population, the same components as adult populations, namely waist circumference, blood pressure, fasting glucose, fasting triglyceride, and fasting HDL-C, are used to diagnose MS. However, consensus is lacking about a single unified definition of pediatric MS. The difficulties developing 
diagnostic criteria for pediatric MS stem from the rapid growth and hormonal changes during puberty, physiologic insulin resistance and its effect on lipid metabolism, and gender differences in fat mass and distribution. ${ }^{45)}$ Among the many diagnostic criteria suggested for pediatric MS, the modified NCEP-ATP III criteria by Cook et al., ${ }^{46)}$ International Diabetes Federation (IDF) criteria, ${ }^{47)}$ and the criteria by de Ferranti et al. ${ }^{48)}$ are widely used (Table 3).

The reported prevalence of MS in children and adolescents varies widely among definitions and study populations. ${ }^{49)}$ In Korean youth, the prevalence of MS was as follows: $13.7 \%$ (males, 14.7\%; females, 12.6\%) among those aged $12-19$ years in 1999-2012 according to the criteria by de Ferranti et al. criteria; ${ }^{50)} 5.7 \%$ (males, $5.8 \%$; females, $5.5 \%$ ) among those aged 10-18 years in 2010-2012 according to the modified NCEPATP III criteria; ${ }^{51)}$ and 1.8\% (males, 1.9\%; females, 1.7\%) among those aged 10-19 years in 2011-2014 according to the IDF criteria. ${ }^{52)}$ Among US youth, the prevalence of MS was 4.2\% (males, 6.1\%; females, 2.1\%) among those aged 12-19 years in 1988-1994 according to the modified NCEP-ATP III criteria ${ }^{46}$; 12.9\% for Mexican Americans, 10.9\% for non-Hispanic whites, and 2.5\% for non-Hispanic Blacks aged 12-19 years in 19881994 according to the criteria by de Ferranti et al. ${ }^{48)}$; and $4.5 \%$ (males, 6.7\%; females, 2.1\%) among those aged 12-17 years in 1999-2004 according to the IDF criteria. ${ }^{53)}$

Although the pathogenesis of MS is not fully understood, obesity, insulin resistance, inflammation, and their interplay are considered cornerstones of MS that affect the development and progression of each of its components. ${ }^{54)}$ Moreover, genetic and environmental risk factors are known to contribute to the development of MS, such as family history, female sex, decreased physical activity, increased sedentary time, and smoking. ${ }^{55)}$

The long-term consequences of MS in childhood are T2D, CVD, and other obesity-related disorders in adulthood. Youth with MS have a 2-3 times higher risk of developing T2D in adulthood than those without MS. ${ }^{56}$ MS in childhood showed an increased odds ratio of 14.6 for adult CVD in a 25 -year follow-up study. ${ }^{57)}$ Moreover, MS in childhood is more likely to track into adulthood. ${ }^{56,57)}$

The treatment of MS in children and adolescents consists of lifestyle modifications and specific treatment for each component of MS ${ }^{58)}$ Lifestyle modification includes weight reduction with a healthy diet, increased physical activity, and decreased sedentary time. At least 20 minutes of daily moderate to vigorous physical activity is recommended. ${ }^{2)}$ Engagement of the entire family is required to ensure effective lifestyle changes. Hypertension should first be managed with lifestyle interventions such as reduced salt intake, weight reduction, and increased physical activity. If hypertension persists after 6 months of lifestyle changes, pharmacological treatment should be considered. ${ }^{59)}$ In cases of MS, angiotensin-converting enzyme inhibitors, angiotensin receptor blockers, or calcium channel blockers are recommended for the treatment of hypertension. ${ }^{59,60)}$ Treatments for prediabetes, T2D, and dyslipidemia are described in the sections above.

\section{Polycystic ovary syndrome}

PCOS is characterized by otherwise unexplained hyperandrogenism, ovulatory dysfunction, and polycystic ovarian morphologic features. ${ }^{60)}$ PCOS is among the most common endocrine disorders of women of reproductive age, with a prevalence of 5\%-10\%. ${ }^{61)}$ The prevalence of PCOS in adolescents differs among criteria, ranging from $3.4 \%$ to $11.0 \%{ }^{62)}$; however, there are no epidemiological data on PCOS in Korean adolescents. PCOS in adolescents is associated with decreased quality of life, ${ }^{63)}$ mental health problems, ${ }^{64,65)}$ metabolic disturbances, and long-term poor cardiovascular and reproductive outcomes. ${ }^{66)}$

Although the pathophysiology of PCOS remains to be determined, hyperandrogenism, insulin resistance, and imbalanced gonadotropin secretion are key contributors. ${ }^{60)} \mathrm{PCOS}$ is com. monly observed in overweight or obese women, and the increasing prevalence of obesity may substantially influence the development of PCOS in susceptible individuals. ${ }^{60)}$ Nonetheless, obesity and other adipose tissue-related factors can aggravate pre-existing clinical, hormonal, and metabolic features in women with PCOS and may play a crucial role in the progression and/ or maintenance of PCOS. ${ }^{60)}$ Recent studies revealed that genetic and environmental factors are associated with the development of PCOS. ${ }^{67)}$

The diagnosis of PCOS in adolescents is based on clinical and biochemical characteristics. However, consensus is lacking on the diagnostic criteria for PCOS among youth. The common presenting symptoms and signs of PCOS include menstrual irregularity, including oligomenorrhea and amenorrhea, signs of insulin resistance, such as acanthosis nigricans, and signs of hyperandrogenism, including hirsutism and acne. ${ }^{60)}$ Laboratory tests are performed to confirm hyperandrogenism, exclude other causes, and evaluate accompanying metabolic disturbances. ${ }^{68)}$ Pelvic ultrasonography might be helpful for excluding other causes of hyperandrogenism such as tumors. Making the diagnosis of PCOS in adolescents might be challenging because discriminating between physiological anovulation during puberty and ovulatory dysfunction in PCOS is demanding.

The treatment goals of PCOS are restoring a normal menstrual cycle, decreasing the signs of hyperandrogenism, improving quality of life, preserving fertility, and reducing the long-term risk of metabolic, cardiovascular, and reproductive outcomes. ${ }^{69,70)}$ The management of adolescents with PCOS should be individualized. Lifestyle modification is the first-line intervention for the treatment of PCOS, including weight reduction through a healthy diet and increased physical activity. Combined oral contraceptives (COCs) are the first-line pharmacologic treatment for PCOS to improve menstrual regularity and reduce androgen excesses. Anti-androgens could be used in conjunction by those who are unresponsive to COCs. ${ }^{67)}$ Metformin, an insulin-sensitizing agent, is recommended for patients with PCOS and dysglycemia. ${ }^{67}$ Metformin improves metabolic disturbances and menstrual irregularities. Topical treatment of the local effects on hirsutism may be selectively applied. ${ }^{67)}$ More 
data on pharmacologic therapy for adolescents with PCOS are required.

\section{Central precocious puberty}

CPP, which is caused by premature activation of the hypothalamic-pituitary-gonadal (HPG) axis, results in the early manifestation of secondary sexual characteristics. ${ }^{71)} \mathrm{CPP}$ is defined as breast development before 8 years of age in girls and testicular enlargement before 9 years of age in boys. ${ }^{72)}$

Obesity is associated with the early initiation of pubertal timing. ${ }^{73)}$ The recent increase in the prevalence of pediatric obesity might be associated with secular trends toward an earlier onset of puberty. Many epidemiologic studies revealed that pediatric obesity is associated with early puberty. ${ }^{74,75)}$ In Korea, the prevalence of CPP has been increasing with obesity ${ }^{76}$ ) and the menarcheal age has been decreasing. ${ }^{77)}$ In obese children, insulin resistance with compensatory hyperinsulinemia and hyperandrogenism are the putative factors that initiate early HPG axis activation. ${ }^{78)}$ Adipokines, including leptin and adiponectin, which affect kisspeptin release, can also stimulate the initiation of puberty. ${ }^{79)}$

CPP is confirmed by a gonadotropin-releasing hormone $(\mathrm{GnRH})$ stimulation test in children with early signs of puberty and greater bone age than chronological age. ${ }^{80)}$ The optimal cutoff value of peak $\mathrm{GnRH}$ stimulated luteinizing hormone level for identifying children with CPP is $\geq 5 \mathrm{IU} / \mathrm{L}$. All boys with CPP and girls diagnosed with CPP before the age of 6 years should undergo brain imaging to screen for a central nervous system etiology. ${ }^{71)}$

The treatment of CPP halts the progression of the rapid development of pubertal signs, prevents the impairment of final adult height, and mitigates psychological issues. ${ }^{71)}$ The treatment of choice is the regular injection of the depot formulation of GnRH agonist. ${ }^{81)}$ In Korea, 1-, 3-, and 6-month depot formulations have been approved. The long-term use of $\mathrm{GnRH}$ agonists is generally safe. ${ }^{71)}$

\section{Conclusion}

With the increased prevalence of pediatric obesity, endocrine comorbidities also show increasing trends, including prediabetes and T2D, dyslipidemia, MS, PCOS, and CPP. These cardiometabolic risks in childhood track into adulthood. Therefore, maintaining a healthy weight and preventing obesity are of critical importance. In obese children and adolescents, the early implementation of obesity management through a multidisciplinary team approach and screening for comorbidities are required. In cases of comorbidities, appropriate management and/or specialist referrals are necessary.

\section{Footnote}

Conflicts of interest: No potential conflict of interest relevant to this article was reported.

ORCID:

Jae Hyun Kim @ https://orcid.org/0000-0002-0203-7443

Jieun Lee $@$ https://orcid.org/0000-0002-9776-4204

\section{References}

1. Obesity: preventing and managing the global epidemic. Report of a WHO consultation. World Health Organ Tech Rep Ser 2000;894:i-xii, 1-253.

2. Styne DM, Arslanian SA, Connor EL, Farooqi IS, Murad MH, Silverstein $\mathrm{JH}$, et al. Pediatric obesity-assessment, treatment, and prevention: an Endocrine Society clinical practice guideline. J Clin Endocrinol Metab 2017;102:709-57.

3. NCD Risk Factor Collaboration (NCD-RisC). Worldwide trends in bodymass index, underweight, overweight, and obesity from 1975 to 2016: a pooled analysis of 2416 population-based measurement studies in 128.9 million children, adolescents, and adults. Lancet 2017;390:2627-42.

4. Oh K, Jang MJ, Lee NY, Moon JS, Lee CG, Yoo MH, et al. Prevalence and trends in obesity among Korean children and adolescents in 1997 and 2005. Clin Exp Pediatr 2008;51:950-5.

5. Kim JH, Moon JS. Secular trends in pediatric overweight and obesity in Korea. J Obes Metab Syndr 2020;29:12-7.

6. Nam HK, Kim HR, Rhie YJ, Lee KH. Trends in the prevalence of extreme obesity among Korean children and adolescents from 2001 to 2014. J Pediatr Endocrinol Metab 2017;30:517-23.

7. Simmonds M, Llewellyn A, Owen CG, Woolacott N. Predicting adult obesity from childhood obesity: a systematic review and meta-analysis. Obes Rev 2016;17:95-107.

8. Skinner AC, Perrin EM, Moss LA, Skelton JA. Cardiometabolic risks and severity of obesity in children and young adults. N Engl J Med 2015; 373:1307-17.

9. Weihe P, Spielmann J, Kielstein H, Henning-Klusmann J, WeihrauchBluher S. Childhood obesity and cancer risk in adulthood. Curr Obes Rep 2020;9:204-12.

10. Weihrauch-Bluher S, Schwarz P, Klusmann JH. Childhood obesity: increased risk for cardiometabolic disease and cancer in adulthood. Metabolism 2019;92:147-52.

11. Sonntag D, Ali S, De Bock F. Lifetime indirect cost of childhood overweight and obesity: A decision analytic model. Obesity (Silver Spring) 2016;24:200-6.

12. Sonntag D, Ali S, Lehnert T, Konnopka A, Riedel-Heller S, Konig HH. Estimating the lifetime cost of childhood obesity in Germany: results of a Markov model. Pediatr Obes 2015;10:416-22.

13. Castorani V, Polidori N, Giannini C, Blasetti A, Chiarelli F. Insulin resistance and type 2 diabetes in children. Ann Pediatr Endocrinol Metab 2020;25:217-26.

14. American Diabetes Association. 2. Classification and diagnosis of diabetes: standards of medical care in diabetes-2021. Diabetes Care 2021; 44:S15-33.

15. Abbasi A, Juszczyk D, van Jaarsveld CHM, Gulliford MC. Body mass index and incident type 1 and type 2 diabetes in children and young adults: a retrospective cohort study. J Endocr Soc 2017;1:524-37.

16. Defronzo RA. Banting Lecture. From the triumvirate to the ominous octet: a new paradigm for the treatment of type 2 diabetes mellitus. Diabetes 2009;58:773-95.

17. Valaiyapathi B, Gower B, Ashraf AP. Pathophysiology of type 2 diabetes in children and adolescents. Curr Diabetes Rev 2020;16:220-9.

18. Fu Z, Gilbert ER, Liu D. Regulation of insulin synthesis and secretion and pancreatic Beta-cell dysfunction in diabetes. Curr Diabetes Rev 2013; 
9:25-53.

19. Arslanian S, Bacha F, Grey M, Marcus MD, White NH, Zeitler P. Evaluation and management of youth-onset type 2 diabetes: a position statement by the American Diabetes Association. Diabetes Care 2018; 41:2648-68.

20. Copeland KC, Zeitler P, Geffner M, Guandalini C, Higgins J, Hirst K, et al. Characteristics of adolescents and youth with recent-onset type 2 diabetes: the TODAY cohort at baseline. J Clin Endocrinol Metab 2011; 96:159-67.

21. Lee J, Lee YA, Kim JH, Lee SY, Shin CH, Yang SW. Discrepancies between glycosylated hemoglobin and fasting plasma glucose for diagnosing impaired fasting glucose and diabetes mellitus in Korean youth and young adults. Diabetes Metab J 2019;43:174-82.

22. Zeitler P, Arslanian S, Fu J, Pinhas-Hamiel O, Reinehr T, Tandon N, et al. ISPAD Clinical Practice Consensus Guidelines 2018: type 2 diabetes mellitus in youth. Pediatr Diabetes 2018;19 Suppl 27:28-46.

23. Brar PC. Update on the current modalities used to screen high risk youth for prediabetes and/or type 2 diabetes mellitus. Ann Pediatr Endocrinol Metab 2019;24:71-7.

24. Pinhas-Hamiel O, Dolan LM, Daniels SR, Standiford D, Khoury PR, Zeitler P. Increased incidence of non-insulin-dependent diabetes mellitus among adolescents. J Pediatr 1996;128:608-15.

25. Writing Group for the SEARCH for Diabetes in Youth Study Group, Dabelea D, Bell RA, D'Agostino RB Jr, Imperatore G, Johansen JM, et al. Incidence of diabetes in youth in the United States. JAMA 2007; 297:2716-24.

26. Andes LJ, Cheng YJ, Rolka DB, Gregg EW, Imperatore G. Prevalence of prediabetes among adolescents and young adults in the United States, 2005-2016. JAMA Pediatr 2020;174:e194498.

27. Cho EH, Shin D, Cho KH, Hur J. Prevalences and management of diabetes and pre-diabetes among Korean teenagers and young adults: results from the Korea National Health and Nutrition Examination Survey 2005-2014. J Korean Med Sci 2017;32:1984-90.

28. Kim MS, Kim JH. Cardiometabolic risk factors and metabolic syndrome by severity of obesity in Korean children and adolescents: data from the Korea National Health and Nutrition Examination Survey 2007-2018 [Abstract]. In: KSSO Annual Spring Conference 2021; 2021 March 2627; Seoul, Korea.

29. Magge SN, Silverstein J, Elder D, Nadeau K, Hannon TS. Evaluation and treatment of prediabetes in youth. J Pediatr 2020;219:11-22.

30. American Diabetes Association. 13. Children and adolescents: standards of medical care in diabetes-2021. Diabetes Care 2021;44:S180-99.

31. DiMeglio LA, Acerini CL, Codner E, Craig ME, Hofer SE, Pillay K, et al. ISPAD Clinical Practice Consensus Guidelines 2018: glycemic control targets and glucose monitoring for children, adolescents, and young adults with diabetes. Pediatr Diabetes 2018;19 Suppl 27:105-14.

32. Tamborlane WV, Barrientos-Perez M, Fainberg U, Frimer-Larsen H, Hafez M, Hale PM, et al. Liraglutide in children and adolescents with type 2 diabetes. NEngl J Med 2019;381:637-46.

33. Bolling CF, Armstrong SC, Reichard KW, Michalsky MP, Section on Obesity SOS. Metabolic and bariatric surgery for pediatric patients with severe obesity. Pediatrics 2019;144:e20193224.

34. Donaghue KC, Marcovecchio ML, Wadwa RP, Chew EY, Wong TY, Calliari LE, et al. ISPAD Clinical Practice Consensus Guidelines 2018: microvascular and macrovascular complications in children and adolescents. Pediatr Diabetes 2018;19 Suppl 27:262-74.

35. Kopin L, Lowenstein C. Dyslipidemia. Ann Intern Med 2017;167:ITC8196.

36. McGill HC Jr, McMahan CA, Zieske AW, Sloop GD, Walcott JV, Troxclair DA, et al. Associations of coronary heart disease risk factors with the intermediate lesion of atherosclerosis in youth. The Pathobiological Determinants of Atherosclerosis in Youth (PDAY) Research Group. Arterioscler Thromb Vasc Biol 2000;20:1998-2004.

37. Expert Panel on Integrated Guidelines for Cardiovascular Health and Risk Reduction in Children and Adolescents; National Heart, Lung, and Blood Institute. Expert Panel on Integrated Guidelines for Cardiovascular Health and Risk Reduction in Children and Adolescents: summary report. Pediatrics 2011;128 Suppl 5(Suppl 5):S213-56.

38. Lim JS, Kim EY, Kim JH, Yoo JH, Yi KH, Chae HW, et al. 2017 Clinical practice guidelines for dyslipidemia of Korean children and adolescents. Ann Pediatr Endocrinol Metab 2020;25:199-207.

39. Vekic J, Zeljkovic A, Stefanovic A, Jelic-Ivanovic Z, Spasojevic-Kalimanovska V. Obesity and dyslipidemia. Metabolism 2019;92:71-81.

40. Yang S, Hwang JS, Park HK, Lee HS, Kim HS, Kim EY, et al. Serum lipid concentrations, prevalence of dyslipidemia, and percentage eligible for pharmacological treatment of Korean children and adolescents; data from the Korea National Health and Nutrition Examination Survey IV (2007-2009). PLoS One 2012; 7:e49253.

41. Kit BK, Kuklina E, Carroll MD, Ostchega Y, Freedman DS, Ogden CL. Prevalence of and trends in dyslipidemia and blood pressure among US children and adolescents, 1999-2012. JAMA Pediatr 2015;169:272-9.

42. Shin JH, Cheong JI, Cheuh HW, Yoo JH. Limitations of current screening methods for lipid disorders in Korean adolescents and a proposal for an effective detection method: a nationwide, cross-sectional study. Ann Pediatr Endocrinol Metab 2020;25:265-71.

43. Reaven GM. Banting lecture 1988. Role of insulin resistance in human disease. Diabetes 1988;37:1595-607.

44. National Cholesterol Education Program (NCEP) Expert Panel on Detection, Evaluation, and Treatment of High Blood Cholesterol in Adults (Adult Treatment Panel III). Third Report of the National Cholesterol Education Program (NCEP) Expert Panel on Detection, Evaluation, and Treatment of High Blood Cholesterol in Adults (Adult Treatment Panel III) final report. Circulation 2002;106:3143-421.

45. Wang HH, Lee DK, Liu M, Portincasa P, Wang DQ. Novel insights into the pathogenesis and management of the metabolic syndrome. Pediatr Gastroenterol Hepatol Nutr 2020;23:189-230.

46. Cook S, Weitzman M, Auinger P, Nguyen M, Dietz WH. Prevalence of a metabolic syndrome phenotype in adolescents: findings from the third National Health and Nutrition Examination Survey, 1988-1994. Arch Pediatr Adolesc Med 2003;157:821-7.

47. Zimmet P, Alberti KG, Kaufman F, Tajima N, Silink M, Arslanian S, et al. The metabolic syndrome in children and adolescents - an IDF consensus report. Pediatr Diabetes 2007;8:299-306.

48. de Ferranti SD, Gauvreau K, Ludwig DS, Neufeld EJ, Newburger JW, Rifai N. Prevalence of the metabolic syndrome in American adolescents: findings from the Third National Health and Nutrition Examination Survey. Circulation 2004;110:2494-7.

49. Reisinger C, Nkeh-Chungag BN, Fredriksen PM, Goswami N. The prevalence of pediatric metabolic syndrome-a critical look on the discrepancies between definitions and its clinical importance. Int J Obes (Lond) 2021;45:12-24.

50. Moon S, Park JS, Ahn Y. The cut-off values of triglycerides and glucose index for metabolic syndrome in American and Korean adolescents. J Korean Med Sci 2017;32:427-33.

51. Kim S, So WY. Prevalence of metabolic syndrome among Korean adolescents according to the National Cholesterol Education Program, Adult Treatment Panel III and International Diabetes Federation. Nutrients 2016;8:588.

52. Seo JY, Kim JH. Validation of surrogate markers for metabolic syndrome and cardiometabolic risk factor clustering in children and adolescents: a nationwide population-based study. PLoS One 2017;12:e0186050.

53. Ford ES, Li C, Zhao G, Pearson WS, Mokdad AH. Prevalence of the metabolic syndrome among U.S. adolescents using the definition from the International Diabetes Federation. Diabetes Care 2008;31:587-9.

54. Tagi VM, Giannini C, Chiarelli F. Insulin resistance in children. Front Endocrinol (Lausanne) 2019;10:342.

55. Wittcopp C, Conroy R. Metabolic syndrome in children and adolescents. Pediatr Rev 2016;37:193-202.

56. Magnussen CG, Koskinen J, Chen W, Thomson R, Schmidt MD, Srinivasan SR, et al. Pediatric metabolic syndrome predicts adulthood metabolic syndrome, subclinical atherosclerosis, and type 2 diabetes mellitus but is no better than body mass index alone: the Bogalusa Heart Study and the Cardiovascular Risk in Young Finns Study. Circulation 2010;122:1604-11. 
57. Morrison JA, Friedman LA, Gray-McGuire C. Metabolic syndrome in childhood predicts adult cardiovascular disease 25 years later: the Princeton Lipid Research Clinics Follow-up Study. Pediatrics 2007;120: 340-5.

58. Tagi VM, Samvelyan S, Chiarelli F. Treatment of metabolic syndrome in children. Horm Res Paediatr 2020;93:215-25.

59. Flynn JT, Kaelber DC, Baker-Smith CM, Blowey D, Carroll AE, Daniels $\mathrm{SR}$, et al. Clinical practice guideline for screening and management of high blood pressure in children and adolescents. Pediatrics 2017;140: e20171904.

60. Dumesic DA, Oberfield SE, Stener-Victorin E, Marshall JC, Laven JS, Legro RS. Scientific statement on the diagnostic criteria, epidemiology, pathophysiology, and molecular genetics of polycystic ovary syndrome. Endocr Rev 2015;36:487-525.

61. Wang S, Alvero R. Racial and ethnic differences in physiology and clinical symptoms of polycystic ovary syndrome. Semin Reprod Med 2013; 31:365-9.

62. Naz MSG, Tehrani FR, Majd HA, Ahmadi F, Ozgoli G, Fakari FR, et al. The prevalence of polycystic ovary syndrome in adolescents: a systematic review and meta-analysis. Int J Reprod Biomed 2019;17:533-42.

63. Trent M, Austin SB, Rich M, Gordon CM. Overweight status of adolescent girls with polycystic ovary syndrome: body mass index as mediator of quality of life. Ambul Pediatr 2005;5:107-11.

64. Dokras A, Clifton S, Futterweit W, Wild R. Increased risk for abnormal depression scores in women with polycystic ovary syndrome: a systematic review and meta-analysis. Obstet Gynecol 2011;117:145-52.

65. Dokras A, Clifton S, Futterweit W, Wild R. Increased prevalence of anxiety symptoms in women with polycystic ovary syndrome: systematic review and meta-analysis. Fertil Steril 2012;97:225-30.e2.

66. Fields EL, Trent ME. Treatment considerations for the cardiometabolic signs of polycystic ovary syndrome: a review of the literature since the 2013 Endocrine Society Clinical practice guidelines. JAMA Pediatr 2016; 170:502-7.

67. Ibanez L, Oberfield SE, Witchel S, Auchus RJ, Chang RJ, Codner E, et al. An international consortium update: pathophysiology, diagnosis, and treatment of polycystic ovarian syndrome in adolescence. Horm Res Paediatr 2017;88:371-95.

68. Cooney LG, Dokras A. Beyond fertility: polycystic ovary syndrome and long-term health. Fertil Steril 2018;110:794-809.

69. Trent M, Gordon CM. Diagnosis and management of polycystic ovary syndrome in adolescents. Pediatrics 2020;145:S210-8.

70. Kostopoulou E, Anagnostis P, Bosdou JK, Spiliotis BE, Goulis DG. Polycystic ovary syndrome in adolescents: pitfalls in diagnosis and management. Curr Obes Rep 2020;9:193-203.

71. Carel JC, Leger J. Clinical practice. Precocious puberty. N Engl J Med 2008;358:2366-77.

72. Latronico AC, Brito VN, Carel JC. Causes, diagnosis, and treatment of central precocious puberty. Lancet Diabetes Endocrinol 2016;4:265-74.

73. Burt Solorzano CM, McCartney CR. Obesity and the pubertal transition in girls and boys. Reproduction 2010;140:399-410.

74. Brix N, Ernst A, Lauridsen LLB, Parner ET, Arah OA, Olsen J, et al. Childhood overweight and obesity and timing of puberty in boys and girls: cohort and sibling-matched analyses. Int J Epidemiol 2020;49:83444.

75. Li W, Liu Q, Deng X, Chen Y, Liu S, Story M. Association between obesity and puberty timing: a systematic review and meta-analysis. Int J Environ Res Public Health 2017;14:1266.

76. Kim YJ, Kwon A, Jung MK, Kim KE, Suh J, Chae HW, et al. Incidence and prevalence of central precocious puberty in Korea: an epidemiologic study based on a national database. J Pediatr 2019;208:221-8.

77. Lee MH, Kim SH, Oh M, Lee KW, Park MJ. Age at menarche in Korean adolescents: trends and influencing factors. Reprod Health 2016;13:121.

78. McCartney CR, Blank SK, Prendergast KA, Chhabra S, Eagleson CA, Helm KD, et al. Obesity and sex steroid changes across puberty: evidence for marked hyperandrogenemia in pre- and early pubertal obese girls. J
Clin Endocrinol Metab 2007;92:430-6.

79. Nieuwenhuis D, Pujol-Gualdo N, Arnoldussen IAC, Kiliaan AJ. Adipokines: a gear shift in puberty. Obes Rev 2020;21:e13005.

80. Ab Rahim SN, Omar J, Tuan Ismail TS. Gonadotropin-releasing hormone stimulation test and diagnostic cutoff in precocious puberty: a mini review. Ann Pediatr Endocrinol Metab 2020;25:152-5.

81. Bangalore Krishna K, Fuqua JS, Rogol AD, Klein KO, Popovic J, Houk CP, et al. Use of gonadotropin-releasing hormone analogs in children: update by an international consortium. Horm Res Paediatr 2019;91:357-72.

82. Chi X, Yu D, Ju L, Zhang J, Zhao L. Prevalence of diabetes and change among 7 to 17 years old children and adolescents in China in 2002-2012. Wei Sheng Yan Jiu 2018;47:705-15.

83. Wang Z, Zou Z, Wang H, Jing J, Luo J, Zhang X, et al. Prevalence and risk factors of impaired fasting glucose and diabetes among Chinese children and adolescents: a national observational study. Br J Nutr 2018;120:8139.

84. Wallace AS, Wang D, Shin JI, Selvin E. Screening and diagnosis of prediabetes and diabetes in US children and adolescents. Pediatrics 2020; 146:e20200265.

85. Dabelea D, Mayer-Davis EJ, Saydah S, Imperatore G, Linder B, Divers J, et al. Prevalence of type 1 and type 2 diabetes among children and adolescents from 2001 to 2009. JAMA 2014;311:1778-86.

86. Khanolkar AR, Amin R, Taylor-Robinson D, Viner R, Warner J, Stephenson T. Ethnic minorities are at greater risk for childhood-onset type 2 diabetes and poorer glycemic control in England and Wales. J Adolesc Health 2016;59:354-61.

87. Lee JH, Kim YM, Kwak MJ, Kim SY, Kim HJ, Cheon CK, et al. Incidence trends and associated factors of diabetes mellitus in Korean children and adolescents: a retrospective cohort study in Busan and Gyeongnam. Ann Pediatr Endocrinol Metab 2015;20:206-12.

88. Urakami T, Miyata M, Yoshida K, Mine Y, Kuwabara R, Aoki M, et al. Changes in annual incidence of school children with type 2 diabetes in the Tokyo metropolitan area during 1975-2015. Pediatr Diabetes 2018; 19:1385-92.

89. Wu H, Zhong J, Yu M, Wang H, Gong W, Pan J, et al. Incidence and time trends of type 2 diabetes mellitus in youth aged 5-19 years: a populationbased registry in Zhejiang, China, 2007 to 2013. BMC Pediatr 2017;17: 85 .

90. Mayer-Davis EJ, Lawrence JM, Dabelea D, Divers J, Isom S, Dolan L, et al. Incidence trends of type 1 and type 2 diabetes among youths, 20022012. NEngl J Med 2017;376:1419-29.

91. Ding W, Cheng H, Yan Y, Zhao X, Chen F, Huang G, et al. 10-Year trends in serum lipid levels and dyslipidemia among children and adolescents from several schools in Beijing, China. J Epidemiol 2016;26:637-45.

92. Park SI, Suh J, Lee HS, Song K, Choi Y, Oh JS, et al. Ten-year trends of metabolic syndrome prevalence and nutrient intake among Korean children and adolescents: a population-based study. Yonsei Med J 2021; 62:344-51

93. Xu T, Liu J, Liu J, Zhu G, Han S. Relation between metabolic syndrome and body compositions among Chinese adolescents and adults from a large-scale population survey. BMC Public Health 2017;17:337.

94. Vanlancker T, Schaubroeck E, Vyncke K, Cadenas-Sanchez C, Breidenassel C, Gonzalez-Gross M, et al. Comparison of definitions for the metabolic syndrome in adolescents. The HELENA study. Eur J Pediatr 2017; 176:241-52

95. Reuter CP, Burgos MS, Barbian CD, Renner JDP, Franke SIR, de Mello ED. Comparison between different criteria for metabolic syndrome in schoolchildren from southern Brazil. Eur J Pediatr 2018;177:1471-7.

How to cite this article: Lee J, Kim JH. Endocrine comorbidities of pediatric obesity. Clinical and Experimental Pediatrics 2021;64:319-27. https://doi.org/10.3345/cep.2021.00213 